\title{
Infecciones en Obstetricia y Ginecología
}

\author{
Newten G. Osborne, M. D., Ph. D \\ Profesor asociado. Escuela de Medicina UNIVERSi. \\ DAD DE CONNECTICUT - FARMINGTON, CON- \\ NECTICUT
}

Las infecciones en obstetricia y qinecología han sido causa de profunda preocupación para médicos a través de los años. Es difícil encontrar una fuente única que presente una clasificación adecuada sobre infecciones pélvicas. ya que la participación de las varias disciplinas médicas que se conciernen con problemas médicos que ocurren en la pelvis ha sido limitada

Debido a la falta de atención unificada y uniforme que este serio problema merece, el galeno concienzudo frecuentemente parte con la idea de que infecciones en obstetricia y ginecologia se tratan por medio de una serie de ritos misteriosos que tienen una base lógica limitada y raramente siguen las reglas del método científico. Antibióticos se tratan como pociones mágicas que se administran por lo general de noche, y se les da nombres complicados, que cambian en cuanto la pronunciación correcta se aprende, de modo que los magos responsables del cuido de pacientes afectados por los espíritus pestilentes no logren control completo de la magia antimicrobiana.

No hay un método simple para captar y dominar con maestría los problemas infecciosos en obstetricia y ginecología, y no se espera resolver este problema con esta presentación. Sin embargo, diré de salida que es posible atacar el problema en forma lógica y organizada. Es esencial mantener un diá- logo constante con el laboratorio de microbiología y tener en cuenta que resultados de laboratorio adquieren significado cuando se interpretan a base de la situación clínica en el momento en que se toman las muestras y no a base de valores absolutos.

Los avances científicos sobre factores responsables por la expresión de la morbilidad infecciosa, no permitirán que el concepto que hoy se acepta como dogma resista la prueba imparcial del tiempo y del estudio científico organizado. La importancia de dominar los conceptos corrientes, reside en el hecho de que tal conocimiento nos permitirá entender y posiblemente adaptar nuevos conceptos en cuanto se agreguen al inventorio del conocimiento científico médico.

Los efectos desvastadores de infecciones en obstetricia y ginecología están escritos en páginas que describen algunas de las horas más negras de la historia médica pero que también cuentan de las luchas más heroicas y sublimes de hombres y mujeres dedicados al bienestar de la humanidad.

Aun cuando los avances han sido impresionantes, y en algunos casos, los resultados casi milagrosos, la lucha contra la morbimortalidad infecciosa continúa sin haber logrado el golpe decisivo que a veces parece estar a nuestro alcance. 
Mi objetivo es el de poner en alto relieve métodos por los cuales se pueden reducir riesgos de complicaciones infecciosas en nuestros pacientes y en particular, en el área de la medicina materno-infantil. En pocas palabras, lo que se necesita es la utilización al máximo de los conocimientos actuales de modo que se pueda tomar la mayor ventaja posible de nuestro arsenal terapéutico actual.

El médico necesita categorizar infecciones en obstetricia y ginecología a base de la presentación clínica y microbiológica. Para lograr este sistema de categorias, se necesitan conocimientos básicos sobre factores predisponentes, de modo que se busquen en forma organizada cuando se hace la evaluación inicial. También es necesario conocer la forma correcta de tomar muestras de cultivo, para que los datos que nos presenta el laboratorio reflejen resultados que tienen su base en la realidad cle un proceso médico. De otra forma, nuestra información se basará en datos ficticios que además de ser inútiles, pueden ser causa de complicaciones severas para pacientes. Por último, nuestro conocimiento clínico y su correlación con datos de laboratorio. nos servirán solamente en proporción directa con nuestro entendimiento sobre la función de antibióticos en relación con la susceptibilidad bacteriana en el proceso infeccioso en cuestión. El conocimiento de los efectos colaterales tóxicos de nuestra terapia nos permitirá hacer una elección inteligente tomando en cuenta riesgos que se miden contra beneficios que se esperan.

Hay un número formidable de preparaciones antimicrobianas (más de cien). El uso lógico de antibióticos es complicado debido a los siguientes factores:

1. La susceptibilidad de la mayoría de bacterias no se puede predecir siempre.

2. La susceptibilidad de micro-organismos varía con el tiempo, sobre todo debido al sobre-uso de drogas populares.
3. Hay una emergencia constante de organismos nuevos con potenciales patogénicos diferentes, y con nombres nuevos y poco familiares.

En la década de los 70 más de 5.000 toneladas de antibióticos se consumieron cada año en los Estados Unidos, Io cual representa un consumo anual de 20 gramos de antibióticos por persona.

Una tercera parte de los pacientes hospitalizados recibieron antibióticos. $\mathrm{De}$ los que recibieron antibióticos, el $30 \%$ lo obtuvieron debido a una infección reconocida, el $34 \%$ en forma profiláctica y el restante debido a síntomas vagos. Exámenes de los casos demos. traron que terapia adecuada se utilizó en solamente el $13 \%$ de los casos an que antibióticos se usaron. Muchos pacientes recibieron antibióticos inefectivos o la dosis adminictrada no fue adecuarta. pero el arupo mayor que utilizó antibióticos en forma inapropiada consistió de casos sin un diagnóstico o sin evidencia microhiológica de infección. La importancia de esta observación es eviderte si se toma en cuenta aue reacciones adversas ocurren en $10-15 \%$ de usuarios .

La utilización adecuada de antibióticos para infecciones en obstetricia es relativamente simple, y los problemas de administración apropiada son senci. llamente los de:

1. Diagnóstico exacto.

2. Conocimiento sobre detalles simples pero sumamente importantes sobre antibióticos.

3. Reconocimiento de las posibilidades y limitaciones de antibióticos en situaciones clínicas específicas.

Si el diagnóstico, el agente etiológico y la terapia que se presume efectiva no se saben con claridad, es necesario tomar cultivos adecuados. Hay que tener en mente que antibióticos por sí solos no pueden resolver infecciones serais en las que la vida del paciente está en peligro. Los antibióticos no son agentes anti-inflamatorios, no son 
agentes cardiotónicos, no actúan como antitoxinas ni tampoco como estimulantes de la circulación.

Medidas auxiliares como el drenaje de absesos, remoción de materiales extraños, terapia fisiológica contra el shock, ventilación adecuada, tratamiento de condiciones asociadas y cuidado superior del personal de enfermería, son extremadamente importantes para el manejo óptimo de pacientes con infecciones severas.

En el sistema de categorización utili. zado para la evaluación de pacientes infectadas en obstetricia y ginecología, hay que examinar críticamente la estructura de la clasificación que se espera utilizar, ya que esta estructura será el ingrediente básico para la estrategia terapéutica que se piense usar.

El proceso del desarrollo de tal clasificación, obliga al médico a delinear el tipo de infección y le permite así tener comunicación clara a base de información exacta con el personal médico encargado del cuido de la paciente. Esta clasificación provee además una guía lógica para la institución de tratamiento adecuado.

Mencionamos que en nuestra categorización de pacientes, una clasificación se basa en criterios clínicos y la otra en criterios microbiológicos (la identificación de organismos patogénicos). Los pacientes infectados se pueden subdividir en aquellos que adquieren la infección en la comunidad, y los que adquieren la infección en el hospital (infección nosocomial).

Las infecciones adquiridas en el hospital son de mucha importancia para el clínico, ya que sugieren que mejoras en la medicina preventiva son posibles. En estos casos, cada situación clínica se debe de evaluar de modo que la de. tección de factores comunes responsables por la infección nosocomial se puedan identificar y corregir. La clasificación que subdivide pacientes en forma tal que infecciones nosocomia- les se identificaron, tiene además la ventaja de proveer una clave para la selección inicial de tratamiento y antibióticos, ya que la mayoría de organismos resistentes se encuentran en este grupo de pacientes. Si un estudio cuidadoso de la microbiología en un servicio dado del hospital se sigue, no solamente se puede tener idea de cual es el probable organismo u organismos que causan problemas, pero también es po. sible identificar la fuente de colonización.

En paises como Colombia las infecciones adquiridas en la comunidad tienen suma importancia, como lo demuestran varios de los trabajos presentados en el XIII Congreso de FECOLSOG, pero la solución de muchos de estos problemas reside más con programas de salud pública, y con la solución de serios problemas éticos y morales, que con avances científicos médicos.

Los estudios del doctor Armando Lozano y sus colaboradores del Instituto Materno Infantil indican una mortalidad aproximada del $10 \%$ de mujeres con aborto séptico, cuando se categorizaban en el grupo con infección grave.

Los doctores Guillermo López-Escobar y Germán Riaño-Gamboa reportan una mortalidad del 11 por 10.000 con el aborto espontáneo y de 73 por 10.000 con el aborto inducido, la mayoria debido a complicaciones sépticas.

Noté que en el resumen presentado por los doctores Jorge Medina y GuiIlermo López-Escobar, la tasa de mortalidad de 50 por 10.000 pacientes en Bogotá se debió a complicaciones sépticas del aborto en el transcurso de los 5 meses en que se hizo el estudio.

Estos datos demuestran que hay un trabajo enorme por completar si las alarmantes cifras de morbimortalidad materna se van a reducir en Colombia. Mujeres con ruptura de un abseso tubo-ovárico, pielonefritis asociado con el shock séptico, o con sepsis debido a una infección post-obortiva, represen- 
tan ejemplos desafortunadamente muy familiares de mujeres en estado crítico.

La otra subdivisión en nuestra estruc. tura de clasificación para pacientes infectadas en obstetricia y ginecología se basa en el tipo de organismos que se recuperan. Si el organismo proviene del medio ambiente se dice que la paciente tiene una infección con organismos exógenos. La infección se cataloga como endógena si los organismos provienen de la flora normal de la paciente.

La categorización de endógenos y exógenos no es siempre fácil, pues mientras algunos organismos como la Neisseria gonorrhoeae son claramente exógenos, este veredicto no es tan claro cuando se obtienen organismos como estafilococos. La mayoría de las infecciones nosocomiales se deben a organismos endógenos

En todo caso, cuando se obtiene un grupo de infecciones similares en una institución, es necesario hacer una investigación de técnicas quirúrgicas y del personal. La literatura médica está repleta de casos de infección causada por sistemas de venoclisis infectados, organismos que se trazan a la nariz, recto o barba del personal que atiende a pacientes o a ciertos procedimientos con alto riesgo de infección, como es la infección post-operatoria cuando se hace una operación cesárea en una paciente con ruptura prolongada de membranas fetales que ha estado en trabajo de parto, o histerectomía vaginal en la paciente premenopáusica.

La evaluación de la paciente infecta. da debe de tomar en cuenta la relación cronológica de la fiebre con eventos clínicos definidos.

El galeno debe de tener metas realísticas cuando obtiene las muestras para el laboratorio de microbiologia. Una prueba de gram a la media noche posiblemente proveerá más información que un cultivo, si no se tiene el material adecuado de colección o si el laboratorio no trabaja 24 horas al día.
El clínico utiliza la identificación microbiológica sencillamente para asesorar el progreso clínico de la paciente de acuerdo con su respuesta al tratamiento anti-infectivo utilizado. La información es particularmente útil en casos en que no se responde en la forma anticipada a un antibiótico dado.

Cuando se toma la muestra, no se puede perder de vista que cada sistema de órganos que se infecta requiere técnicas diferentes de colección si se quiere aislar el grupo de organismos responsables por el proceso infeccioso. Hay que tener en mente que los modelos clásicos de infección por lo general no se aplican a la obstetricia y ginecología. El modelo de un organismo. una infección, una droga,es común en casos de infecciones en medicina interna. Mecanismos de acción bacteriana sinergística ocurren por lo general en infecciones gineco-obstétricas. Además la vieja clasificación entre patógenos y comensales probablemente no se aplica a la obstetricia y ginecología. Más bien hay un mecanismo aparentemente de organismos que causan infección clínica temprana después de un evento, y por lo general son organismos aeróbi$\cos$, y estos contribuyen a una progresión anaeróbica que resulta en infección clínica tardía con formación de absesos y tromboflebitis séptica.

He tratado de describir un proceso por el cual el médico pueda trazar un modo de acción lógico para el manejo de infecciones serias en obstetricia y ginecología. Con tal conocimiento, es posible que el antibiótico más especifico para los microorganismos probables y con mínima toxicidad para el paciente se utilice

No he tratado de cubrir los sindromes infecciosos ni tampoco el tratamiento de elección para casos específicos, pues sería imposible cubrirlos en el tiempo disponible.

Me gustaría en todo caso que se note que durante la época inicial del desarrollo de antibióticos, médicos y epi- 
demiólogos con mucho entusiasmo, pero con un conocimiento limitado de fisiología y ecología bacteriana hicieron la predicción de que las infecciones se relegarian a una posición de importancia insignificante. Después de cuatro décadas encontramos que las infecciones todavía representan uno de los mayores problemas que ponen a prueba el acumen diagnóstico y el juicio terapéutico del gineco-obstetra.

Luego de las enormes contribuciones de gigantes como Koch, Pasteur, Ehrlich, y Semmelweis, para nombrar algunas de las más notables lumbreras, mueren muchas mujeres a causa de infecciones pélvicas. Muchas de ellas mueren a causa de infecciones prevenibles, y demasiado de ellas por negligencia médica.
El médico que por su negligencia permita que la pestilencia y mortalidad visiten la sala hospitalaria, comete un crimen por el cual no existe castigo adecuado. Si se me permite usar la frase del célebre estadista norteamericano, Oliver Wendell Homes, tal persona debe buscar su perdón de Dios, pues el hombre nunca lo perdonará.

Presentado el 6 de diciembre de 1979 al XIII Congreso Colombiano de Obstetricia y Ginecología en Bogotá, Colombia.

Deseo extender mi profundo agradecimiento al comité organizador del con. greso y en especial al doctor Francisco Pardo-Vargas por haberme honrado con su invitación. 